\title{
The syndrome of burnout among Iranian university professors teaching TEFL
}

Entezari, Maryam

Department of English, Khorasan e Razavi Science and Research Branch, Islamic Azad University, Neyshabur, Iran (entezarimaryam@yahoo.com)

Ghafournia, Narjes $\bowtie$

Department of English, Neyshabur Branch, Islamic Azad University, Neyshabur, Iran (na.ghafournia@gmail.com)

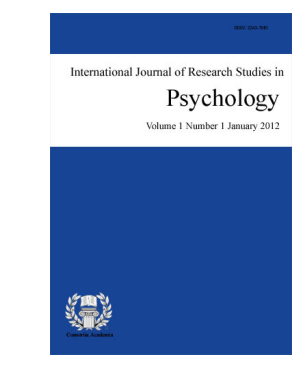

ISSN: 2243-7681 Online ISSN: 2243-769X

OPEN ACCESS

Received: 12 October 2015

\section{Abstract}

This study aimed at finding out whether the role of a teacher in a classroom influences the level of burnout s/he may experience. The teacher's role was investigated in the light of Goffman's Footing theory, according to which the role is classified into three categories of animator, author, and principal. Goffman (1981) believed that an animator is a person who exactly repeats the ideas expressed by the others; an author paraphrases the statement, and the principal is a person who explains her/his original opinions. A total of 30 university professors teaching TEFL at BA and MA levels were chosen and filled Maslach's Burnout Inventory to measure their level of burnout in terms of three subscales of emotional exhaustion, depersonalization, and personal achievement. In addition, a metaphor checklist was given to their students who were asked to select among 21 metaphors, the ones representing animator, author, and principal roles that appropriately described the role of each of the 30 professors. The findings indicated that burnout was lower in the professors who adopted the principal role and higher in those who took on the animator and author roles respectively. The results offer pedagogical implications for the university context.

Keywords: burnout; footing theory; emotional exhaustion; depersonalization; personal accomplishment; metaphor 


\section{The syndrome of burnout among Iranian university professors teaching TEFL}

\section{Introduction}

In recent years, increasing attention has been paid to the phenomenon of burnout. When people feel exhausted from working too hard and give too much of themselves, they suffer from burnout (Küçükoğlu, 2014). Schwarzer and Hallum (2008. p. 154) defined burnout as "a chronic state of exhaustion due to long-term interpersonal stress within human service profession". They believed that burnout is related to the jobs that people are repeatedly exposed to emotionally-charged social situations.

Maslach and Jackson (1984, p. 134) also defined burnout as "a syndrome of emotional exhaustion, depersonalization, and reduced personal accomplishment that can occur among individuals who work with people in some capacity". To put it in more specific words, burnout has three symptoms. Firstly, emotional exhaustion is the most obvious manifestation of this syndrome. It refers to the feeling of being overextended and exhausted from one's work. Emotional exhaustion is not something that is simply experienced rather it triggers a kind of emotional and cognitive distance that a person tries to create from his/her work. Thus, it is followed by the second symptom of burnout, called depersonalization. Depersonalization, defined as the development of negative and indifferent attitudes toward the others, which is an attempt to put a distance between oneself and service recipients.

In a workplace in which a person feels emotionally tired and impersonal to the job environment, s/he is likely to feel ineffective. In fact, gaining a sense of lack of accomplishment is inevitable when one feels exhausted and depersonalized. Consequently, the third symptom of burnout, which reduced personal achievement, appears subsequently. Reduced personal accomplishment is defined as the loss of the feelings of self-competence and not being satisfied with one's achievement (Maslach et al., 2001).

Küçükoğlu (2014) stated that burnout brings about a number of negative effects on the educational outcome. Firstly, the more a teacher suffers from burnout, the more his/her productivity decreases. This is because his/her emotional exhaustion prevents him/her from investing enough in the teaching-learning process. Secondly, lack of interest and loss of energy also demotivate the teachers. This directly and negatively affects the students' motivation and hence their success. The next side effect of burnout is depersonalization that reduces the rapport between the teacher and the students. Lack of a good relationship between a teacher and his/her students can reduce the students' motivation. Finally, burnout turns teachers into irresponsible agents who see no reason to invest serious efforts in teaching profession.

\section{Related review of literature}

Due to the prevalence of burnout syndrome and the side effects it produces on the educational process, many studies have been done to find the underlying roots of burnout. For example, Küçükoğlu (2014) stated that burnout can be the result of both environmental factors such as work overload, low salary, poor classroom environment, and lack of respect for teachers and personality factors like age, self-esteem, and self-confidence.

Exploiting the metaphor of an extinguishing candle to clearly depict the draining of employees' energy to maintain an intense involvement in a commitment, Schaufeli et al. (2009) also mentioned some factors contributing to burnout. Firstly, the increase of demands on employees requires them to be more intensely involved in their jobs. This robs them of the opportunity to rest and regenerate their energy. Such an imbalance between demands and energy makes them feel exhausted. In addition, a conflict between the values of organizations and those of employees leads to the reduction of commitment, distrust, and skepticism, all of which results in the feeling of burnout. Similarly, Maslach and Leiter (1997) stated that demanding, cold, and hostile workplace fades the dedication and commitment to jobs. This turns people into cynical workers, who do 
not get involved in their tasks.

Kovacs (2010) stated that teacher burnout is the result of the chronic perception that the teacher is unable to manage the demands of teaching profession. In fact, there are several factors playing important roles in triggering burnout. They include culture shock, excessive expectations of students, excessive expectations of the institution, and the feeling of being overwhelmed with a heavy workload or the size of the language group.

\subsection{Relationship between burnout and other constructs}

The relationship between burnout and other constructs has been explored in many empirical studies. Specifically, some studies investigated the association between burnout and personality factors. Pishghadam and Sahebjam (2012), for instance, examined the relationship between teacher's personality types, emotional intelligence and burnout. To do so, 147 English language instructors, who work in some English language institutes in Mashhad, were chosen. Three instruments were applied to gather the data: Maslach Burnout Inventory, NEO-Five Factor Inventory, and Bar-On Emotional Quotient Inventory. The result indicated a significant relationship between personality types and emotional intelligence and three dimensions of burnout, namely emotional exhaustion, depersonalization, and reduced personal accomplishment. Firstly, personality features are related to burnout. To put it in more specific words, the participants who showed the highest scores in emotional exhaustion and low scores in personal accomplishment were those who demonstrated high scores in neuroticism and low scores in extroversion. Moreover, high scores in depersonalization are correlated with low scores in agreeableness and conscientiousness. Secondly, there was a significant relationship between low scores in emotional exhaustion, depersonalization, and high scores in personal accomplishment and EQ. Finally, it was concluded that teacher burnout can be predicted regarding personality and emotional intelligence.

Self-efficacy is also a construct that has been studied by many researchers in the burnout domain. For example, Skaalvik and Skaalvik (2010) explored the relationship between teachers' self-efficacy, teachers' burnout, and job satisfaction in 2249 Norwegian teachers in elementary and middle school. The result indicated that teachers' self-efficacy was negatively correlated with the two dimensions of teachers' burnout, namely emotional exhaustion and depersonalization. In addition, job satisfaction was positively related to self-efficacy and negatively related to the emotional exhaustion and depersonalization. This shows that the more a teacher enjoys his/her job, the higher is his/her belief in his/her ability to manage educational goals and the less s/he suffers from burnout.

Although burnout has turned into a topic on which lots of articles have been written, various books have been published, and many conferences have been held, research on tracing the possible influence of the teachers' role on teacher burnout has remained intact and mediocre. Few studies have made an attempt to enlighten the complexity of the interaction between these two constructs. This study not only focused on such an interaction but also investigated the teachers' role from a new perspective through applying Goffman's Footing Theory.

\subsection{Footing theory}

Footing, one of Goffman's theories, introduced in conversation, is defined as the alignment that participants in interaction take with regard to one another (Goffman, 1981). Deckert and Vickers (2011) stated that footing shows the degree to which a speaker shows his own identity in a conversation.

Goffman (1981) believed that, in every conversation, the terms speaker and hearer are quite basic. The term speaker, however, is too oversimplified. This means that it does not have any meaning beyond sound and does not decompose the role of the one who speaks into more detailed elements. Consequently, he introduced the concept of Footing Theory according to which a speaker can adopt the three roles of animator, author, and principal.

An animator is someone who repeats the utterances he holds and expresses the opinions he does not hold. In 
fact, he speaks for someone else and in someone else's words. For instance, reciting a fully memorized text or reading aloud from a prepared script gives the speaker the role of animator. Secondly, an author is someone who reformulates or paraphrases the words having been uttered by someone else. For example, reading off from a text or a group of utterances which has not been memorized gives the speaker the role of author. Finally, a principal is the person who expresses his own original ideas. He is someone who is committed to what he says and states one's original ideas allowing the speaker to change his/her footing (Goffman, 1981).

Footing theory has been applied to the educational setting in a number of studies. Pishghadam and Shirmohammadi (2011), for instance, attempted to pursue the roles of animator, author, and principals in the professors' teaching TEFl at the MA level in both current and ideal situations. To this end, 218 Iranian MA students and graduates were given a metaphor checklist, including 21 metaphors, which represent the three roles. The results revealed that in the current situation the professors dominantly take on animator and author roles respectively. However, the findings describing the professors in the ideal situation indicated that the students preferred their professors to have the principal role. In another study, Pishghadam and Shirmohammadi (2012) explored the roles of 10 professors teaching TEFl at the MA level in the light of Footing theory. This time, however, they used observational data in classroom setting instead of metaphor analysis. In-depth analysis of the transcripts revealed that classroom practices were dominated by the author role taken by the professors.

In a similar vein, Ghapanchi and Talebi (2012) explored the metaphors about university professors' roles in current and ideal situations, chosen by a group of 200 Iranian BA students to identify whether there is any mismatch between the roles that the professors take on currently and the roles they are expected to adopt ideally. To this end, the participants were asked to select the metaphors from a metaphor checklist, which best described their professors in the current and ideal situation. Then, the metaphors were organized according to three roles of animator, author, and principal. Chi-square was conducted to find out whether a significant difference existed among the roles of the professors currently and ideally. The results revealed that the university professors teaching TEFL and English Literature at BA level mostly took on animator and author roles in the current situation while principal and author roles were the roles the students preferred their professors to adopt.

Ghapanchi and Talebi (2012) conducted a comparative study, in which they compared the roles of the professors teaching English literature and TEFL at BA level with those teaching TEFL at MA level. They also exploited metaphor analysis and asked 240 students, studying at BA level and 88 students, studying at MA level to fill out a metaphor checklist. The findings indicated that the dominant role of the professors teaching at BA level was principal while the author role was the dominant role taken by the professors teaching at MA level.

Talebi and Shirmohammadi (2012) aimed at examining whether there is a significant difference among the critical thinking means scores of the professors who adopted the animator, author, or principal role. To achieve this goal, a group of 30 professors, teaching English was selected, and their students $(\mathrm{N}=328)$ were given metaphor checklist in order to choose the metaphors that best characterized the role of each professor. Besides, the professors' critical thinking abilities were measured through Watson-Glaser Critical Thinking Appraisal Test. This was done to find out whether the professors' role differed significantly regarding their critical thinking skills. The result of one-way ANOVA indicated that the critical thinking mean score of the professors taking on the principal role was significantly higher than those adopting the animator or author role.

\subsection{Purpose of the study}

Many studies have been undertaken to find the factors contributing to burnout (e.g. Hakanen et al., 2006; Schaufeli et al., 2009). With regards to the influence of the teachers' role and burnout, there seems to be a lack of research. Pishghadam and Sahebjam (2012), focusing the significance of examining the relationship between the educational context and burnout, have recommended that more studies should be carried out in this field. Therefore, due to the importance of the role that a teacher takes on in the disposition to burnout, and due to the lack of research in this domain, attempts were taken to find the influence of teacher role on teacher burnout in 
order to enlarge our understanding of the factors leading to teacher burnout.

The purpose of this study is to find out whether the professors taking on the animator, author, or principal role are significantly different concerning their level of burnout, measured in terms of three subscales of emotional exhaustion, depersonalization, and personal achievement. Therefore, the present study addressed the following research questions.

$>$ Q1: Is there any significant difference among the emotional exhaustion mean scores of the professors adopting the animator, author, or principal role?

Q2: Is there any significant difference among the depersonalization mean scores of the professors adopting the animator, author, or principal role?

$>$ Q3: Is there any significant difference among the personal achievement mean scores of the professors adopting the animator, author, or principal role?

\section{Methodology}

\subsection{Participants}

This study consisted of two groups of participants. The first group was a total of 161 male and female participants, including $79 \mathrm{BA}$ and $82 \mathrm{MA}$ students, majoring in TEFL. They were studying at Ferdowsi University of Mashhad, Hakim Sabzevari University of Khorasan, Zahedan University, Alzahra University of Tehran, Hasheminejad University of Mashhad, Tabaran University of Mashhad, and Semnan University. They were ranging in age from 20 to 35. The participants were chosen randomly from 254 initial participants. The second group of the participants comprised of 30 professors (females=11, males=19), who had MA or PhD degree and taught English at BA and MA levels. They taught at the universities mentioned above. For both groups of the participants, no distinction was made between the males and females. The 30 professors were randomly selected from linitial 46 professors.

\subsection{Instrumentation}

In order to address the research questions, the following instruments were used.

Maslach's burnout inventory (MBI) - To measure the participants' level of burnout, the Maslach's Burnout Inventory (MBI) was used. The inventory includes 22 items, which measure three subscales: 9 items to measure emotional exhaustion, 5 items to assess depersonalization, and 8 items to test personal accomplishment. The items were scored based on the frequency that the items are scored. The items were on a 7-point frequency scale ranging from (0) "never" to (6) "everyday". Respondents should use this 7-point scale to answer the inventory. For the purpose of this study, the Persian translation of MBI was employed. The questionnaire was checked by some professors in TEFEL, who gave some feedback to improve the content validity of the questionnaire. The reliability index using Cronbach alpha formula was reported to be 0.89 , which was satisfactory.

Metaphor checklist - To determine the dominant role of each of the 30 professors, who were the second group of the participants, the students were asked to answer a metaphor checklist, designed by Ghapanchi and Talebi (2012). This checklist includes one prompt, "My professor is like a. The prompt is followed by some options that determine the professors' dominant roles regarding Goffman's Footing theory. They comprise of 7 metaphors showing the animator role (robot, parrot, copy machine, projector, repeater, microphone, and cassette player), 7 metaphors showing the author role (scaffolder, missionary, cook, puzzle doer, mixer, summarizer, and molasses), and 7 ones determining the principal role (writer, power plant, sun, artist, spring, challenger, and window to the world). The students were required to choose the metaphors that best characterize their attitudes towards each of the 30 professors. Ghapanchi and Talebi (2012) asserted that the checklist enjoyed a high 
content validity as it was substantiated by two experts in the field, and its semantic disambiguation was done by some students who were asked to take the checklist. The reliability of the checklist, which was computed by the Cronbach's Alpha, was reported to be 0.81 for the whole sample. It shows that the results of the checklist are satisfactorily reliable in terms of their internal consistency.

\subsection{Procedure}

First of all, the students were asked to fill out the metaphor checklist and select the metaphors appropriately characterize each of the 30 professors to determine each professor's dominant role. The randomly used metaphors in the metaphor checklist, which were selected by the subjects, were categorized under three roles of animator, author, and principal. Then, the frequency of the metaphors of each group was calculated. Chi-square was run to find out whether there was a significant difference among three kinds of the metaphors chosen by the participants. In doing so, the dominant role of each professor was determined as animator, author, or principal.

In the next stage, to investigate the professors' level of burnout, 30 professors were asked to take Maslach's Burnout Inventory. Each of the professors' level of burnout was specified in terms of three subscales of emotional exhaustion, depersonalization, and personal achievement. In other words, for each professor, three scores were registered for three subscales. To identify whether the professors having the animator, author, or principal role differed significantly concerning three subscales of burnout, one-way ANOVA was employed.

\section{Results}

\subsection{The results of metaphor analysis}

In this phase, the students received a metaphor checklist and were asked to choose the metaphors that described their ideas about the role of each individual professor. Then, Chi-square was separately conducted for each of the professors to check the differences among the selected metaphors and determine every professor's dominant role as animator, author, or principal. Table 1, which was randomly selected as an example, represents the result of Chi-square run for professor number 27. For this table, a detailed data analysis is put forward.

\section{Table 1}

The Results of the Chi-square for the Metaphors about the Professor Number 27

\begin{tabular}{llllll}
\hline & Observed N & Expected N & Df & $x^{2}$ & Sig \\
\hline Animator & 58 & 84 & 2 & 12.66 & .002 \\
Author & 92 & 84 & 2 & & \\
Principal & 102 & 84 & 2 & & \\
Total & 252 & & & & \\
\hline
\end{tabular}

Table 1 presents the results of the Chi-square for the metaphors that represent the role of the professor number 27 as animator, author, and principal and were chosen by his students. As it can be clearly seen, there is a significant difference among the metaphors determining the professor's role as animator, author, and principal $\left(x^{2}=12.66, p<.05\right)$. To put it in more specific words, the metaphors reflecting the author and principal roles $(\mathrm{N}=92$ and $\mathrm{N}=102$ respectively) outnumber what is expected $(\mathrm{N}=84)$ among the rest. The results reveal that the professor number 1 mostly takes on the principal role. On the other hand, the metaphors reflecting the animator role $(\mathrm{N}=58)$ is less than the expected number $(\mathrm{N}=84)$. It shows that the animator role is the least dominant role taken on by the professor.

$$
\text { principal }>\text { author }>\text { animator }
$$

In the same vein, each professor's dominant role was identified as animator, author, or principal based on the comparison between the observed and expected numbers of the metaphors. 


\subsection{The results of the score analysis of three subscales of burnout}

In this phase, 30 professors teaching TEFL were required to fill in Maslach Burnout Inventory. The results of one-way ANOVA, applied to check the differences among the professors' scores of burnout subscales (emotional exhaustion, depersonalization, and personal achievement), are presented in the following tables.

The results of the analysis of the emotional exhaustion scores - Table 2 illustrates the results of one-way ANOVA run to identify whether there is significant differences among the emotional exhaustion mean scores of the professors taking on the animator, author, or principal role.

\section{Table 2}

One-way ANOVA on the Emotional Exhaustion Scores

\begin{tabular}{llllll}
\hline & Sum of squares & df & Mean square & F & Sig \\
\hline Between groups & 4891.65 & 2 & 2445.825 & 106.28 & .000 \\
Within groups & 621.31 & 27 & 23.01 & & \\
Total & 5512.96 & 29 & & & \\
\hline
\end{tabular}

As it is evident in this table, there is a statistically significant difference among the professors in terms of their emotional exhaustion scores $(p<.05)$. Table 3 presents the results of Duncan test on the emotional exhaustion score of the professors taking on the animator, author, or principal role.

\section{Table 3}

The Results of Duncan Test on the Emotional Exhaustion Mean Scores

\begin{tabular}{lcccc}
\hline \multicolumn{1}{c}{ Role } & $\mathrm{n}$ & \multicolumn{3}{c}{ Subset for alpha=.05 } \\
\hline Principal & 8 & 1 & 2 & 3 \\
Author & 12 & 7.5 & & \\
Animator & 10 & & 31.9 & 39.6 \\
sig & & 1.0 & 1.0 & 1.0 \\
\hline
\end{tabular}

Table 3 indicates the results of Duncan test, employed to compare the emotional exhaustion mean scores of each group of the professors adopting the animator, author, or principal role. The principal, author, and animator roles are separately situated in subset 1,2 , and 3 respectively. The results indicate that the professors adopting the animator role suffer from the highest amount of emotional exhaustion among the others. Those taking on the author role are the second group with a high emotional exhaustion level. However, the professors who move beyond the repetition of current intellectual framework act as agents of change and have the least amount of emotional exhaustion.

The results of the analysis of depersonalization scores - Table 4 illustrates the results of one-way ANOVA run to identify whether there is significant differences among the depersonalization mean scores of the professors taking on the animator, author, or principal role.

\section{Table 4}

One-way ANOVA on the Depersonalization Scores

\begin{tabular}{llllll}
\hline & Sum of squares & df & Mean square & F & Sig \\
\hline Between groups & 1822.46 & 2 & 911.23 & 106.28 & .000 \\
Within groups & 209.4 & 27 & 7.75 & & \\
Total & 2031.86 & 29 & & & \\
\hline
\end{tabular}

Regarding the findings shown in the table, there is a statistically significant difference among the professors' depersonalization scores $(p<.05)$. Table 5 presents the results of Duncan test, employed to compare the depersonalization mean scores of each group of the professors adopting the animator, author, or principal role. 
Entezari, M., \& Ghafournia, N.

Table 5

Duncan Test on the Depersonalization Mean Scores

\begin{tabular}{lcccc}
\hline \multicolumn{1}{c}{ Role } & $\mathrm{n}$ & \multicolumn{3}{c}{ Subset for alpha=.05 } \\
\cline { 2 - 5 } & & 1 & 2 & 3 \\
\hline Principal & 8 & 4.5 & 18.5 & \\
$\begin{array}{l}\text { Author } \\
\text { Animator }\end{array}$ & 12 & & & 24.4 \\
sig & 10 & & 1.0 & 1.0 \\
\hline
\end{tabular}

The principal, author, and animator roles are separately situated in subset 1, 2, and 3 respectively. This result indicates that the professors adopting the animator role suffer from the highest amount of depersonalization among the others. Those taking on the author role are the second group with a high depersonalization level. On the other hand, the professors who adopt the principal role have the least amount of depersonalization.

The results of the personal achievement scores - Table 6 illustrates the results of one-way ANOVA run to identify whether there is a significant difference among the personal achievement means scores of the professors taking on the animator, author, or principal role.

\section{Table 6}

One-way ANOVA on the Personal Achievement Scores

\begin{tabular}{llllll}
\hline & Sum of squares & df & Mean square & F & Sig \\
\hline Between groups & 3533.75 & 2 & 1766.87 & 191.65 & .000 \\
Within groups & 248.91 & 27 & 9.21 & & \\
Total & 3782.66 & 29 & & & \\
\hline
\end{tabular}

As it is evident in this table, there is a statistically significant difference among the professors in terms of their personal achievement $(p<.05)$. Table 7 presents the results of Duncan test employed to compare the personal achievement mean scores of each group of the professors adopting the animator, author, or principal role.

Table 7

Duncan Test on the Personal Achievement Mean Scores

\begin{tabular}{llll}
\hline Role & $\mathrm{N}$ & \multicolumn{2}{l}{ Subset for alpha=.05 } \\
\cline { 3 - 4 } & & 1 & 2 \\
\hline Animator & 10 & 13.5 & \\
Author & 12 & 15.92 & 39.25 \\
Principal & 8 & & 1.0 \\
sig & & .09 & \\
\hline
\end{tabular}

In subset 1 , the animator and author roles are situated. The p-value is more than 0.05 , which suggests that no statistically significant difference exists between personal achievement mean scores of the professors who adopt the animator or author role. However, that fact that the principal role is situated in subset 2 reveals that the personal achievement means score of the professors taking on the principal role is significantly higher than the personal achievement mean scores of those adopting the animator or author role.

\section{Discussion and conclusion}

An educational context is potentially demanding as teachers are emotionally, mentally, and physically involved with the teaching profession. Thus, recent and continuing reports of increasing stress among teachers have been the focus of some studies in the last decade (e.g. Whitehead, 2001). Indeed, this stress, technically known as burnout, is a phenomenon of dramatic importance in education. This is because the important role that a teacher plays in the teaching-learning process is undeniable. Thus, any physical or psychological problem, which a teacher experiences can negatively affect the students' learning (Fareh \& Saeed, 2011). Teachers play 
The syndrome of burnout among Iranian university professors teaching TEFL

valuable roles in helping children grow any opportunity to promote their physical and mental health (Küçükoğlu, 2014).

It is against this background that this exploratory study was conducted. It first examined the perceptions of burnout among university professors in terms of three subscales of depersonalization, emotional exhaustion, and personal achievement. Then, each subscale was explored considering the roles that the professors played in the classrooms. These roles, animator, author, or principal are based on the Footing theory, proposed by Goffman (1981). The findings of this study are so worthwhile. The reason is although burnout is a serious problem, teacher burnout studies have lacked a firm theoretical basis, which explains how the role of a teacher can affect the level of burnout s/he may experience.

Concerning the first question of this study, it was found that emotional exhaustion is the highest among the professors who take on the animator role and the lowest among those who adopt the principal role with the professors playing the author role in the middle. A teacher who takes on the animator role is the one whose teaching practice is centered on repetition of what is provided in the textbooks. In other words, his/her main responsibility seems to be the repetition of the concepts presented in the materials. Challenging the current intellectual framework, expressing original ideas, and projecting his/her own personality are the elements lacking in such a teacher's teaching method. Over time, teaching profession will turn into a routine and monotonous task, in which creativity and innovation have no place. In terms of intrapersonal subscale, the teacher adopting animator role will experience emotional detachment from his/her profession. Thus, the feelings of mental depletion, overextension, and emotional exhaustion are set to follow.

On the other hand, a teacher who adopts the principal role provides the opportunities for critical consciousness. The teacher makes a shift in the teaching activity away from following taken-for-granted knowledge to challenging the information. In fact, s/he acts as a transformative intellectual person, whose main concern is not dispensing knowledge but projecting his/her identity. For such a teacher, the aim of education is not projection of knowledge but critical thinking. It seems that teaching profession, which is demanding on its own, will not emotionally exhaust teachers. This is because every day, it provides teachers with new challenges, which are self-motivating enough to fade the feeling of emotional depletion.

The results of this study indicated that the emotional exhaustion of a teacher who adopts the author role is much closer to the teacher who takes on the animator role than to the one who plays the principal role. This shows that to reduce the amount of emotional exhaustion, the teachers are demanded to make a radical shift in their teaching practice toward critical consciousness. The findings of this study are of significance since they emphasize the contribution of critical and creative teacher-training programs to effective language teaching programs. In other words, the findings of this study emphasize the training of creative teachers with high critical thinking ability, who can adopt principal role effectively. Critical teachers can enable studiers to ponder over the tasks thoughtfully and learn the target language effectively under a non- monotonous atmosphere.

The same holds true for the second question of this study. It was also found that depersonalization is the highest among the professors who take on the animator role and the lowest among those who adopt the principal role with the professors playing the author role in the middle. A teacher whose dominant teaching method is repetition of the information of the textbooks is someone who is recitefull rather than insightful and repeater rather than challenger. To put in other words, the teacher is not an agent of change critically judging the realm of knowledge. A dynamic cognitive framework is lacking in his/her classroom. This means that little by little his/her identity will be lost in the concepts produced by the others. This leads to a kind of emotional and cognitive distance between the teacher and the educational elements, including curriculum, administrators, and, most importantly, students.

The teachers who adopt the principal roles, however, pave the opposite way. Challenging the concepts, expressing their own original ideas, and reforming the current intellectual framework, not only cause a distance between teachers and educational world, but also let them enter the realm of knowledge. In fact, teachers 
contribute to the world of knowledge. As a result, they may experience less depersonalization as they do not have impersonal attitudes toward their profession.

Similar to the level of emotional exhaustion, the level of depersonalization of a teacher who takes on the author role falls somewhere between that of the teacher who adopts the animator and principal roles although it is much closer to the amount of depersonalization that a teacher playing the animator role experiences. This means that avoiding repetition or simplification of the concepts presented in the textbooks and expressing original ideas instead may help the teachers to get rid of the syndrome of depersonalization.

Considering the third question of the study, it was found that a teacher who takes on the principal role enjoys higher personal achievement in comparison to the one who adopts the animator or principal role. A teacher who plays the principal role moves beyond transmission of knowledge, provides the opportunities for challenging the flow of information, and has a critical outlook toward the information. Critically analyzing and questioning the claims put forward by the other thinkers, the teacher does not fit into the current cognitive framework but reforms the trend of knowledge. This means that the teacher is not the consumer of knowledge rather s/he is the producer of some original ideas. Consequently, the feeling of productivity and efficiency will be higher for such a teacher. Indeed, a teacher who is a principal will benefit from higher self-competency and personal achievement.

Nevertheless, the teachers who take on the animator or author roles nearly equally have lower feeling of personal achievement. This is because they are simply concerned with repetition, clarification, or simplification of the concepts of the books. They neither open the space for challenging the current knowledge nor critically evaluate concepts and theories. As they present no original ideas to contribute to educational world, they can be considered to be the consumers rather than the producers of knowledge. Hence, the feelings of productivity, self-competency, and satisfaction from one's achievement will fade away.

Overall, it can be concluded that burnout is lower in the teachers who adopt the principal role and higher in those who take on the animator and author roles respectively. That the level of burnout changes based on the role that a teacher plays in the classroom reflects the ideas held by Dorman (2003) and Huebner and Huberty (1984). They also believed that depending on whether a teacher is active and involved creatively and critically in the teaching process or passive and unmotivated, a teacher may experience varying degrees of burnout.

There can be few doubts about the severity of the syndrome of burnout in educational organizations in general and in the life of teachers in particular. Despite the complexity of the problem, the researcher emphasizes the point that teacher burnout must be seen not as an individual problem, but as an occupational issue for which the administrative and organizational authorities are primarily responsible. In fact, it is the time for managerial administrators to understand that organization-based preventive strategies will reduce the poor performance due to burnout. Teacher training sessions, performance evaluation, and regular performance feedback should aim at training teachers, who are critical thinkers, challengers of current intellectual framework, and contributors to the field of knowledge. Administrators and supervisors should make the teachers aware of the need to make a radical shift in their teaching practice. It is necessary to accentuate the fact that repetition and paragraphing of the information of the textbooks should be replaced by expressing original idea. To make sure that the teachers are on the right track, an efficient monitoring system should be established to supervise the teachers' teaching practice.

\section{References}

Deckert, S. K., \& Vickers, C. H. (2011). An introduction to sociolinguistics: Society and Identity. New York: Continuum.

Dorman, J. (2003). Testing a model for teacher burnout. Australian Journal of Educational \& Developmental Psychology, 3, 35-47.

Fareh, S., \& Saeed, A. Z. (2011).The teacher as researcher in the context of language teaching. Procedia Social 
and Behavioral Sciences, 15, 153-159. http://dx.doi.org/10.1016/j.sbspro.2011.03.066

Ghapanchi, Z., \& Talebi, F. (2012). A comparison between roles of professors teaching English Literature or TEFl at BA level and professors teaching TEFL at MA level in the light of Goffman's footing theory. World Journal of Education, 2, 33-44. http://dx.doi.org/10.5430/wje.v2n1p39

Ghapanchi, Z., \& Talebi, F. (2012). Exploring Iranian university students' beliefs about professors' roles: A quantitative study. World Journal of English Language 2, 57-63. http://dx.doi.org/10.5430/wjel.v2n1p57

Goffman, E. (1981). Forms of talk. Pennsylvania: University of Pennsylvania Press.

Hakanen, J. J., Bakker, A. B., \& Schaufeli, W. B. (2006). Burnout and work engagement among teachers. Journal of School Psychology, 43, 495-513. http://dx.doi.org/10.1016/j.jsp.2005.11.001

Huebner, E. S., \& Huberty, T. (1984). Burnout among rural school psychologists. Research in Rural Education, 2(3), 95-99.

Kovacs, G. (2010). Stressors leading to teacher burnout in adult education and ways of prevention helping the language teacher. AARMS, 9, 117-123.

Küçükoğlu, H. (2014). Ways to cope with teacher burnout factors in ELT classrooms. Procedia Social and Behavioral Sciences, 116, 2741-2746. http://dx.doi.org/10.1016/j.sbspro.2014.01.647

Maslach, C., \& Jackson, S. (1984). Burnout in organizational settings. Applied Social Psychology Annual, 5, 133-153.

Maslach, C., \& Leiter, M. P. (1997). The truth about burnout: How organizations cause personal stress and what to do about it. US: Jossey-Bass.

Maslach, C., Schaufeli, W. B., \& Leiter, M. P. (2001). Job burnout. Annual Reviews, 52, 397-422. http://dx.doi.org/10.1146/annurev.psych.52.1.397

Pishghadam, R., \& Sahebjam, S. (2012). Personality and emotional intelligence in teacher burnout. The Spanish Journal of Psychology, 15(1), 227-236. http://dx.doi.org/10.5209/rev_SJOP.2012.v15.n1.37314

Pishghadam, R., \& Shirmohammadi, S. (2011). Investigation into the roles of Iranian professors teaching TEFL: A study based on Goffman's footing theory. Journal of Academic and Applied Studies, 1(4), 42-58.

Pishghadam, R., \& Shirmohammadi, S. (2012). Professional Identity in Iran's higher education: A case of EFL professors. Journal of Educational and Social Research, 2(1), 317-328.

Schaufeli, W. B., Leiter, M. P., \& Maslach.C. (2009). Burnout: 35 years of research and practice. Career Development International, 14(3) 204-220. http://dx.doi.org/10.1108/13620430910966406

Schwarzer, R., \& Hallum, S. (2008). Perceived teacher self-efficacy as a predictor of job stress and burnout: Mediation Analyses. The International Association of Applied Psychology, 57, 152-171. http://dx.doi.org/10.1111/j.1464-0597.2008.00359.x

Skaalvik, E., \& Skaalvik, S. (2010). Teacher self-efficacy and teacher burnout: A study of relations. Teaching and Teacher Education, 26, 1059-1069. http://dx.doi.org/10.1016/j.tate.2009.11.001

Talebi, F., \& Shirmohammadi, S. (2012). Investigating Iranian professors' roles and their critical thinking abilities. International Journal of Linguistics, 4(3), 656-670. http://dx.doi.org/10.5296/ijl.v4i3.1793

Whitehead, A. J. (2001). Teacher burnout: A study of occupational stress and burnout in New Zealand school teachers. Unpublished doctoral thesis, Massey University of Albany. 
Entezari, M., \& Ghafournia, N. 